\title{
SURVEYING, MODELING AND 3D REPRESENTATION OF A WRECK FOR DIVING PURPOSES: CARGO SHIP "VERA"
}

\author{
A. Ktistis, P. Tokmakidis, K. Papadimitriou * \\ Laboratory of Topography (LabTop), School of Rural and Surveying Engineering, Faculty of Engineering, 54124, Aristotle \\ University of Thessaloniki, Greece - a.ktistis@gmail.com, ptokmaki@gmail.com, paki@auth.gr
}

\section{Commission II}

KEY WORDS: Underwater Recording, Point Cloud, Model Reconstruction, 3D Representations, Wreck Diving, Community Engagement

\begin{abstract}
:
This paper presents the results from an underwater recording of the stern part of a contemporary cargo-ship wreck. The aim of this survey was to create 3D representations of this wreck mainly for recreational diving purposes. The key points of this paper are: a) the implementation of the underwater recording at a diving site; b) the reconstruction of a $3 \mathrm{~d}$ model from data that have been captured by recreational divers; and c) the development of a set of products to be used by the general public for the ex situ presentation or for the in situ navigation. The idea behind this project is to define a simple and low cost procedure for the surveying, modeling and 3D representation of a diving site. The perspective of our team is to repeat the proposed methodology for the documentation and the promotion of other diving sites with cultural features, as well as to train recreational divers in underwater surveying procedures towards public awareness and community engagement in the maritime heritage.
\end{abstract}

\section{INTRODUCTION}

\subsection{Wreck Diving}

People are interested in shipwrecks for various reasons. They want to know what is/was contained and to understand what circumstances caused them. Archaeologists and historians are engaging in research as wrecks are tangible historical resources that give direct access to the past (UNESCO, 2001). Additionally, wrecks are becoming man-made reefs that accommodate aquatic life and occasionally those might be sites with appreciable concentrations or specific kind of life to monitor. Concerning the diving industry, wrecks are significant attractions as they combine both cultural and natural features to be explored by the general public.

Only what is known and valued by society is sought by it to be protected. Underwater cultural heritage, the yet too «invisible» heritage, has thus still a long way to go to get society caring and valuing it. Communicating about the significance of submerged heritage to more people through media, publications, public access and interpretation can increase awareness of its importance in society and thereby increase the demand for its protection and study. It is through understanding, that society values and gives significance to cultural heritage, whilst seeking its protection and conservation by developing different means to reach these goals, as well as its enjoyment (Silva, 2016). In this context the surveying and the representations of shipwrecks for awareness purposes are in line with the general principles of the Manual for Activities directed at Underwater Cultural Heritage (UNESCO, 2013).

\subsection{Legal Aspects}

In Greece, wrecks of ships, submarines and aeroplanes that was shank more than fifty years ago are considered as cultural heritage, according to the law (3028/2002, FEK A' 153/28-62002) About the Antiquities and the Cultural Heritage. A protection zone is defined at $300 \mathrm{~m}$ surrounding the wreck. Conclusively, this law protects the underwater heritage in the Greek seas (wrecks older than 50 years).

In order to characterize a wreck as an underwater monument (proportionally to the land monuments) it is required the appropriate documentation, resulting from an adequate scientific research. Such work has to be done for each wreck separately and issuing the permission for a maritime research may take up to eight months. Those facts, apart from leaving some legal gaps until the characterization of a wreck (Tripontikas, 2016), result in long times for the declaration acts and moreover for the protection of the underwater monuments.

\subsection{Community Engagement}

Responsible public access at underwater sites with cultural assets has benefits for the local community, in economical and sustainable development terms (Silva, 2014). Whilst this engagement with the recreational diving community and the non-diving public instils an enthusiasm for the maritime environment and its conservation (Roberts and Trow, 2002), the involvement of the local dive clubs who can act as local custodians has proved beneficial (Beattie-Edwards, 2016).

Besides the dive professionals that are already providing services with direct access to the numerous submerged heritage features (e.g. underwater museums and dive trails), there are 
many diving or non-diving amateurs that are documenting and presenting underwater cultural assets on the web (e.g. ww2.wrecks.com, aviationarchaeology.gr, wreckdiving.gr). The contribution of community engagement has already been a mean of accurately identifying and recording previously unknown maritime heritage and moreover, public interpretation can be an important part of the management and protection of sites in remote locations (Roberts et al, 2016).

\section{STUDY AREA}

At the central part of Greece (region of Thessaly), between the mainland (the peninsula of Mt. Pelion) and Skiathos island (Figure 1) there is a reef, named Lefteris, which extends at a length of about 180 meters (from north to south) and at a width of about $80 \mathrm{~m}$ (from east to west). This small rock is marked with a navigation light on it and has a heavy history behind.

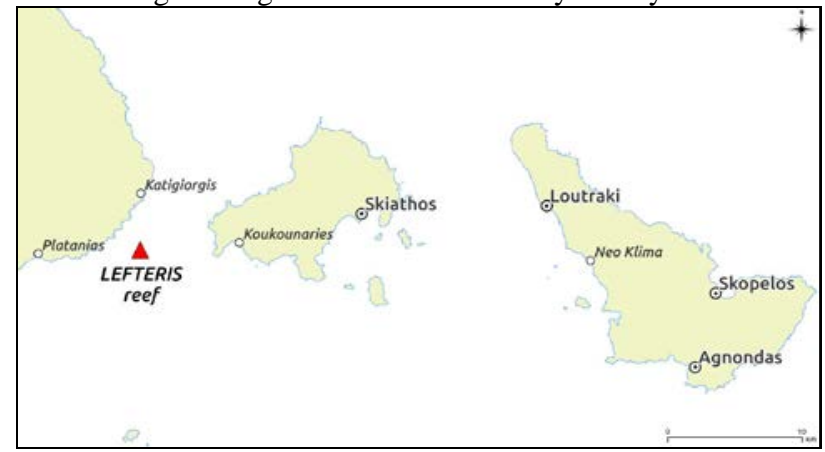

Figure 1. The map displays the site (red triangle), the main ports and the small harbours (white dots) at the study area.

\subsection{History}

According to Herodotus during the invasion of the Persians in Greece, at least three of the Persian galleys of king Xerxes ran into the reef and sank. After that event King Xerxes ordered the Persians to carry blocks of stone weight of $700-1.200$ pounds and built on top of the reef a stone column to highlight the risk and to ensure safe navigation (Figure 2). It is considered the most ancient construction known until today (2.5 centuries prior to the lighthouse of Alexandria), segments of which were pulled up with the help of the divers in 1928.

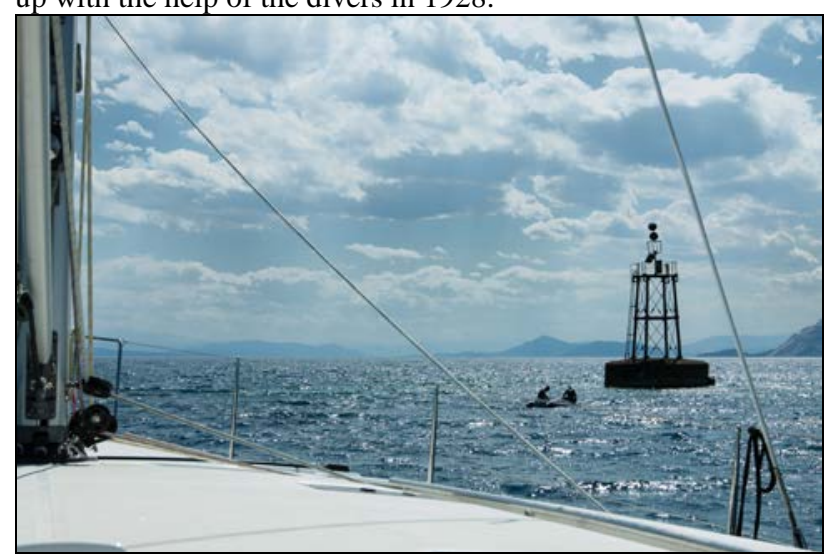

Figure 2. Lefteris reef with its modern navigation light

\subsection{Cargo Ship "Vera”}

Cargo ship "Vera" (58 meters long) was built in 1956 in Holland and crashed on the reef in 1999. It was carrying rust from Larymna Fthiotis (central Greece) to Thessaloniki (northern Greece) and the crew was transferred safely to the mainland (at the small harbour of Platanias). The ship remained aground for some time because the weather conditions did not encourage its detachment. A few months later, it broke into two parts and sank.

Today, it lies to depths between 17 meters and 28 meters. Its bow is standing at a vertical position (at the deeper part), while it's stern lies at the bottom on its side (at the shallower part) a few meters further. This study, refers to the stern (shallower) part of the wreck which is approximately 20 meters long, 10 meters tall and 10 meters wide (Figure 3 ).

\subsection{Dive Site}

Over the years the parts of this wreck have been decorated with fishing equipment (nets and lines). Altogether, merged with the natural formation of the reef, have become a marine life refuge. The site accommodates typical coastal Mediterranean marine fishes and occasionally passing groups of bigger pelagic species may be encountered. In combination with the long history of the site, the mystic atmosphere of the wreck and its ideal depth, provides the conditions for a particular experience for divers of all levels of training. The maximum depth of the dive at the stern (shallow) part of the shipwreck is $17 \mathrm{~m}$.

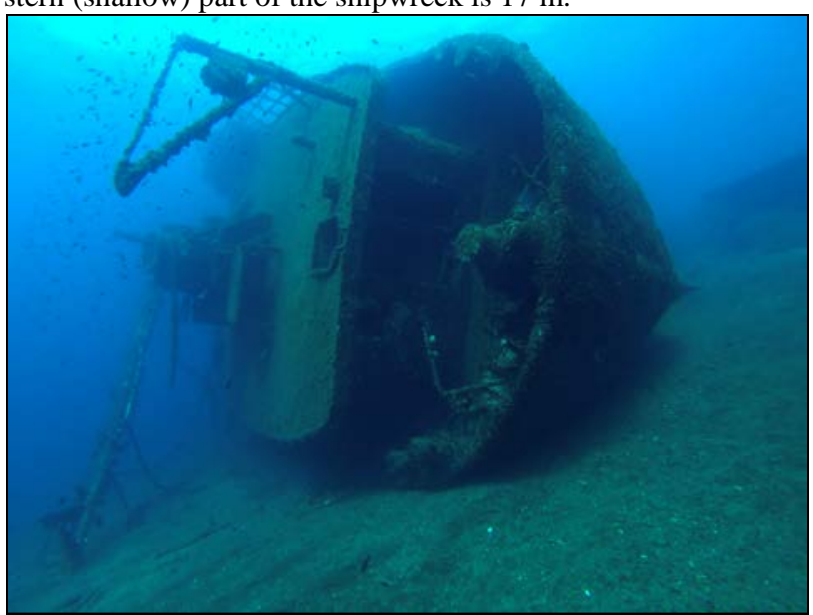

Figure 3. The stern part of the shipwreck lies on its side over a sandy bottom at the depth of approximately $17 \mathrm{~m}$.

The site is accessible by boat from the ports of Skiathos and Skopelos or from the nearby small harbours (Katigiorgis, Koukounaries, Neo Klima and Platanias). There are five dive centres at the wider area and three of them (one at Skopelos and two at Skiathos) are usually organizing dive excursions at Lefteris reef.

\subsection{Site Selection}

The specific site is a landmark for the local community and it is becoming known among the divers that are visiting the area. The shipwreck is relatively new (was sank eighteen years ago), which in turn means that it has not been characterized yet as an underwater monument. So, there is no requirement for a special permission to dive there. Considering the dive planning, the site can be explored or photographed in a single dive (within the training limitations of most certified, recreational divers). In the meanwhile the stern part, which was selected for this study, is interesting on its own to complete a diving experience there.

From a technical aspect, there are surfaces with various dimensions and lighting conditions. The shipwreck's size is 
moderate and its shape, after it was broken, is complex in terms of construction details and structural deformations. Thus, it depicts a typical case scenario for the assessment of the bellow demonstrated methodology for the surveying, the modeling and the $3 \mathrm{D}$ representation of a wreck. Finally, the developed material for the purposes of ex situ presentation and in situ navigation of such a popular site is expected to be distributed more easily and to be evaluated promptly by the professional and recreational divers at the local diving centers.

\section{METHODOLOGY}

The presented methodology concerns the dive planning for an underwater survey during two subsequent recreational dives, the use of special equipment that not rarely is owned by divers and the data processing for the reconstruction of a shipwreck's model.

\subsection{Dive Planning}

The planning was made for two subsequent dives. The objective of the first one was the investigation of the site and during the second dive the recording was performed. Both dives were supported by a surface team (supervisor and rescue diver) on a vessel (sailing yacht). The first dive lasted 30 minutes and the second 45 minutes with a safety stop ( $3 \mathrm{~min}$ at $5 \mathrm{~m}$ ) each. The maximum depth of the dives was $19 \mathrm{~m}$ and air was used as a breathing gas. Two divers have participated, one holding a Rescue Diver certification and the other being an Advanced Open Water Diver.

\subsection{Special Equipment}

Apart from the basic personal diving equipment the following were used during the underwater survey: a) a $12 \mathrm{Mp}$ action camera (for underwater use); b) a 22Mp DSLR camera (operating in a submersible housing rated to $60 \mathrm{~m}$ depth) without artificial lighting; c) a plastic measuring tape (30 m long); and d) a blank slate with pencil. Additionally, for the processing of data were used: a laptop (when on board) and a desktop PC (at the office), both running "Agisoft - Photoscan" a 3D modeling (photogrammettric) software.

\subsection{Underwater Survey}

\subsubsection{Site Investigation}

The objective of the first dive was the investigation of the site with specific tasks the capturing of a sequence of pictures that describe the wreck and the measuring of indicative distances for its size. One diver was responsible to handle the action camera, whilst the other one was in charge for taking and keeping notes for the measurements (Figure 4).

Approximately 500 pictures were shot, using the action camera, in time lapse mode (at 2sec interval). After the initial recording with the action camera, several indicative distances were measured between well recognizable points over the wreck. No artificial targets were used, since that would probably increase the complexity of the dive plan or would require additional dives.

The points were selected having in mind an even spatial distribution and the measurements were noted down on a blank slate. Those distances were used for the scale adjustment of the model during the data processing.

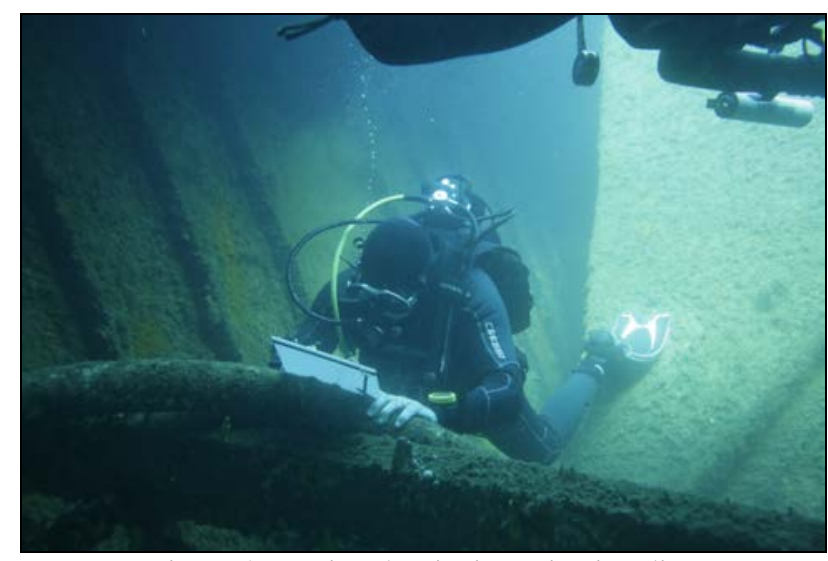

Figure 4. During the site investigation dive

\subsubsection{Camera Trajectory Planning}

After the first dive, the set of pictures from the action camera was processed to create a draft model. This was completed being on board and the model was immediately used for planning in details the following dive. The purpose of this plan was to estimate the optimum camera trajectory around the wreck, considering that: a) the divers should avoid going repetitively to the deeper parts; and b) the wreck should be completely covered by pictures during a single dive. The resulted estimation for the camera trajectory defined a precise dive profile. This profile was sketched on the blank slate for underwater use.

\subsubsection{Recording}

During the second dive, one diver was in charge for following the precise dive plan and for navigating around the wreck without missing out any parts of the wreck. The second diver was responsible for capturing the photographs. Approximately 700 shots were taken manually using the DSLR camera, resulting to a second finest dataset.

\subsection{Model Reconstruction}

In order to test how the software behaves in the situation where the images are taken by multiple divers with a variety of cameras, the two datasets were combined.

\subsubsection{Point Cloud}

Initially the images of both datasets were aligned into the photogrammetric software and the camera positions were estimated in a Cartesian local system. The distances that have been measured on the wrecks surface were used as scale bars to optimize the alignment. Images or specific tie points with great uncertainty have been filtered out, using gradual selection tools, based on the re-projection error, the uncertainty and the accuracy factors etc. After filtering 161.630 points have been left at the sparse point-cloud that have been generated throughout this process. When finished filtering and optimizing the sparse point cloud, a dense pointcloud consisting of 133.851.887 points have been generated.

\subsubsection{Mesh}

A 3D mesh was generated and refined with semi-automatic quality assessment. A manual refinement took place and the needed patches were applied in order to end up with a 
"watertight" (closed) model in order to be used for the 3D printing. The final dense model consists of 26.770.341 3D faces.

\subsubsection{Texture}

Finally the model was textured, using the image data from the DSLR camera only, which has greater quality compared to the action camera (Figure 5).

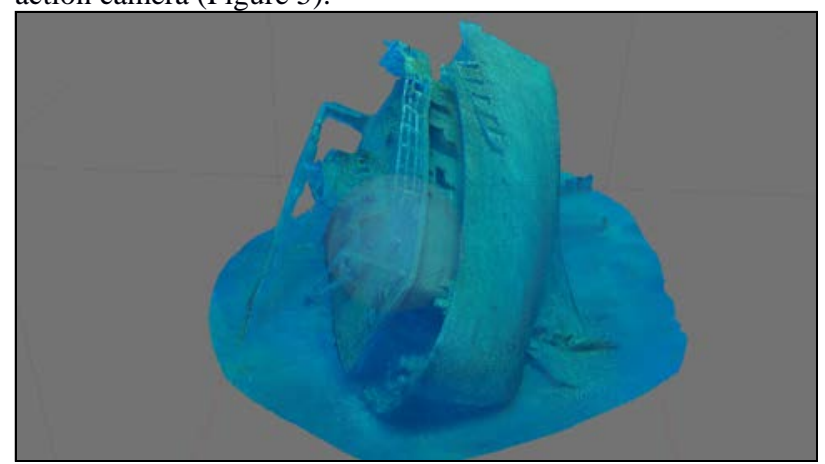

Figure 5. Digital textured model

\subsubsection{Post-Processing and 3D Printing}

Sequentially, using a 3D model editing software, a solid base was added and the creator's names engraved at the bottom of it, in order to prepare the final model for 3D printing. Since the initial model was too dense for the 3D printer to handle, it was decimated and reduced to 1.000 .000 3D faces. After postprocessing, the model was ready for 3D printing.

\subsection{Representations}

Several derivatives can be produced based on the 3D model of a wreck. The scope of this case study are the uses that are applicable to recreational dive planning, promotion of diving services and eventually the attraction of diving tourism at the site of interest.

\subsubsection{Digital Model}

The digital 3D model is the fundamental derivative and can be used either for scientific or commercial purposes. There are a lot of flexible file formats that can be rendered easily, like VRML for use at the Web and in portable devices, OBJ and PLY for use in other post-processing 3D software, STL for 3D printing and even 3D-PDF with measuring capabilities for easier non-expert access.

\subsubsection{D Print}

The 3D model was printed using an FDM (Fused Deposition Modelling) 3D printer on ABS thermoplastic, using a scale of 1:100, in blue color (Figure 6).

A printed 3D model can serve for better understanding of the dive plan at briefing time, can serve as a souvenir for a specific diving site, for wreck causes analysis and also for people that are visually impaired since it is a perfect haptic model. For a very low resolution, low accuracy model an indicative cost is $35 €$ (the model is hollow inside).

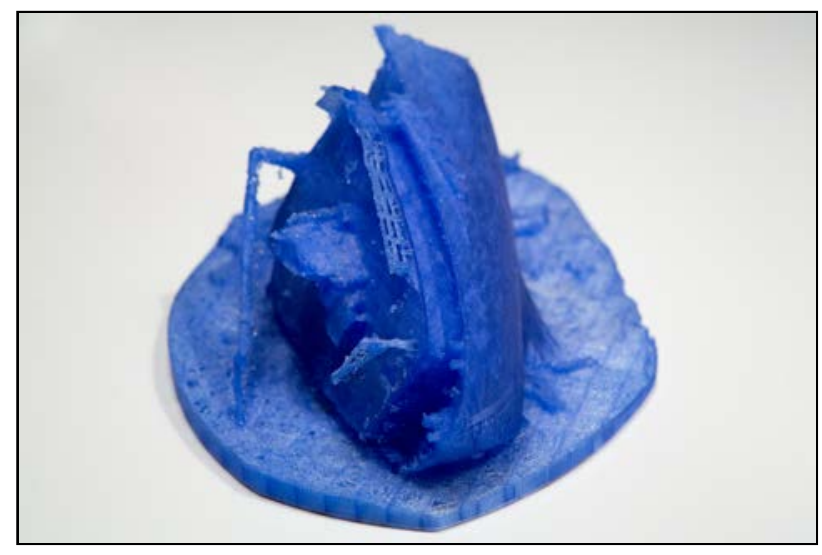

Figure 6. Printed model on ABS thermoplastic

\subsubsection{Wreck Diving Slate}

A wreck diving slate (Figure 7), is a plastic, waterproof, printed slate with all the needed information for diver's navigation and recognition of features on the wreck site.
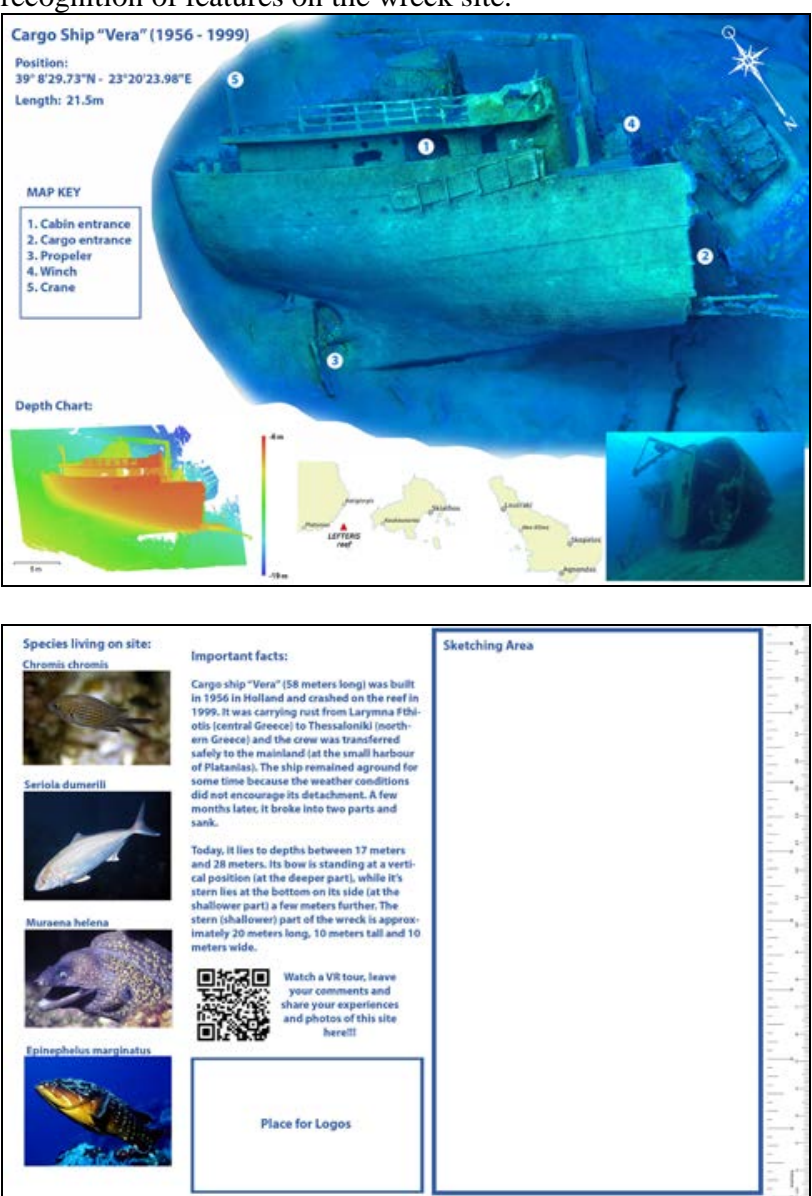

Figure 7. The front and rear sides of the wreck diving slate

It includes: GPS coordinates to find the wreck; sketch (orthophoto) of the wreck with north direction to help navigation and give important information (some depths or depth scale; penetration entrances; interesting locations you must visit ex. Rudder; cargo holders; engine room; photos and description of the species observed on site (marine life); scale of the sketch and ruler; some important historical information for the wreck; space for notes or detail sketching from the diver; 
and URL for the diver to share his information, photos and videos.

\section{CONCLUSIONS}

As 3D representations are supporting the planning of dives, the preparation (briefings) of the participants and the in situ navigation, the products of such a model are expected to be used in many ways from the diving community.

Planning and accomplishing dives for such purposes may become a demanding operation and occasionally require technical diving practices instead of simple recreational ones. In great consideration and in order not to compromise the safety of the divers, is the ability of participants not to focus only on the operation of camera or measuring equipment but also to the contact and communication with other team members. Potential underwater survey divers have to consider depth, extend of the area to be covered, the required time and air supplies and their level of training as major factors for the success of such projects. In this case the diver's team remained well inside the recreational dive limits and that was the initial goal. It is highly recommended though, skill development in swallower water and a comprehensive and thorough dive plan.

At national level, there are few public awareness actions that are targeting to the marine natural environment (e.g. thalassaproject.mom.gr, isea.com.gr) but none for the cultural heritage. On the other hand, members of the diving community in Greece are often accessing maritime cultural features (e.g. wreck diving, thematic underwater trails), and occasionally they are documenting them (photos or video).

During the 5th International Congress on Underwater Archaeology "IKUWA 2014", were presented the positive results for the local and the scientific community (BeattieEdwards, 2016; Pinedo and Zamanillo, 2016; Roberts and Trow, 2002; Roberts et al, 2016; Stefanie, 2016), after the public engagement in projects for the management of underwater heritage (e.g. blogs.wessexarch.co.uk/samphire, www.coronationwreck.org). Towards this direction, Nautical Archaeology Society (www.nauticalarchaeologysociety.org), has been organizing courses for the responsible participation of divers in archaeology (PADI Wreck Detective Specialty). Moreover, the PADI Underwater Survey Diver Specialty has been developed for the training of divers on underwater recording and measuring procedures (Papadimitriou et al, 2016). Such initiatives are expected to support the "responsible non-intrusive access for observing or documenting in situ [our] underwater cultural heritage" (UNESCO, 2001) and to propel community archaeology in the maritime field.

\section{ACKNOWLEDGEMENTS}

The authors would like to thank Skopelos Dive Centre, which has provided the facilities for the preparation of the diving team, the boat for the transportations and the surface support during the dives.

\section{REFERENCES}

Beattie-Edwards, M., 2016. England's Protected Wreck Diver Trails and the Economic Value of a Protected Wreck. In: Proceedings of the 5th International Congress on Underwater Archaeology. A heritage for mankind. Ministerio de Educación, Cultura y Deporte. Cartagena, Spain, pp. 198-212

Rey Da Silva, A., 2014. The Unesco 2001 Convention on the Protection of the Underwater Cultural Heritage, the Development of Underwater Archaeology and the Public Access. In: Proceedings of the 5th Baltic Sea Regional Cultural Heritage Forum. Estonial National Heritage Board. Tallinn, Estonia, pp. 26-31

Rey Da Silva, A., 2016. Designating a Unesco List of Best Practices of Access to underwater cultural heritage. In: Proceedings of the 5th International Congress on Underwater Archaeology. A heritage for mankind. Ministerio de Educación, Cultura y Deporte. Cartagena, Spain, pp. 71-85

Roberts, A., Benjamin, J., McCarthy, J., 2016. Marine Stewardship and Maritime Archaeology in Scotland: Preliminary observations from Project SAMPHIRE. In: Proceedings of the 5th International Congress on Underwater Archaeology. A heritage for mankind. Ministerio de Educación, Cultura y Deporte. Cartagena, Spain, pp. 187-197

Roberts, P., and Trow , S., 2002. Taking to the Water, The Management of Maritime Archaeology in England. Historic England https://www.historicengland.org.uk (2 Dec. 2002).

Papadimitriou, K., Ktistis, A. and Sarakinou, J., 2015. Underwater recording and 3d modeling during a dive training course: a case study at Panormos, Skopelos, Greece. In Journal of Environmental Science and Engineering, A(4), pp. 445-454.

Pinedo, R.O., Zamanillo, L., 2016. Facts and needs in an example of archaeological tourism. In: Proceedings of the 5th International Congress on Underwater Archaeology. A heritage for mankind. Ministerio de Educación, Cultura y Deporte. Cartagena, Spain, pp. 225-226

Stefanile, M., 2016. Underwater Cultural Heritage, Tourism and Diving Centers: The case of Pozzuoli and Baiae (Italy).In: Proceedings of the 5th International Congress on Underwater Archaeology. A heritage for mankind. Ministerio de Educación, Cultura y Deporte. Cartagena, Spain, pp. 213-224

Tripontikas P., 2016. Wrecks in the Greek Seas, 1830 - 1951. http://tripontikas.wixsite.com/seawrecks (9 Sep. 2016)

UNESCO, 2001. Convention on the protection of the underwater cultural heritage.

UNESCO, 2013. Manual for Activities Directed at Underwater Cultural Heritage. Guidelines to the Annex of the UNESCO 2001 Convention. 